Article

\title{
The Potential of Plantain Residues for the Ghanaian Bioeconomy-Assessing the Current Fiber Value Web
}

\author{
Tim K. Loos ${ }^{1,2}, * \mathbb{C}$, Marlene Hoppe ${ }^{3}$, Beloved M. Dzomeku ${ }^{4}$ and Lilli Scheiterle ${ }^{2}$ \\ 1 Food Security Center, University of Hohenheim, Wollgrasweg 43, 70599 Stuttgart, Germany \\ 2 Institute of Agricultural Sciences in the Tropics (Hans-Ruthenberg-Institute), University of Hohenheim, \\ Wollgrasweg 43, 70599 Stuttgart, Germany; lilli.scheiterle@uni-hohenheim.de \\ 3 C.S.P. Consulting und Service für Pflanzliche Rohstoffe GmbH, Schnorrstraße 70, 01069 Dresden, Germany; \\ marlenehoppe@web.de \\ 4 CSIR-Crops Research Institute, P.O. Box 3785 Fumesua-Kumasi, Ghana; bmdzomeku@gmail.com \\ * Correspondence: timloos@uni-hohenheim.de; Tel.: +49-711-459-22548
}

Received: 27 September 2018; Accepted: 13 December 2018; Published: 18 December 2018

check for updates

\begin{abstract}
An essential part in the concept of any emerging bioeconomy includes the sustainable use of biomass as a resource for industrial raw materials. Focusing on the increasing demand for natural fibers, it will be necessary to identify alternative sources without compromising food security. Here, untapped potential lies in the use of plantain residues. Yet, it is unclear how or whether this can be activated. This article investigates the current situation in Ghana as a major plantain producer in Africa. Based on data collected with participatory tools, expert interviews, and group discussions, we (i) assess predominant plantain production structures, (ii) derive a stakeholder network map identifying institutional challenges, and (iii) discuss the potential starting points for linking the supply side with the national or international fiber market. Results indicate that there is substantial interest of private enterprises for high quality fibers. Despite traditional knowledge, after fruit harvest the fiber rich plantain pseudostems usually remain in the field. From an institutional point of view, key stakeholders and structures exist that could boost the establishment of a sustainable plantain based fiber value web. Key to such an endeavor, however, would be to pilot activities, including technology transfer of suitable innovations from other countries.
\end{abstract}

Keywords: plantain residues; fiber; value web; bioeconomy; Ghana

\section{Introduction}

Plantain is an essential crop for many rural households in the southern regions of Ghana. With more than $90 \%$ of the cultivated area belonging to smallholder farmers [1], it not only provides staple food to the population, but also serves as a key source of rural income which is reflected in contributing about $13 \%$ to the agricultural gross domestic product [2,3]. It is increasingly becoming an integral part of the agro-food industry [1]. Next to Cameroon and Uganda, Ghana is the main producer of plantain fruit in Africa. In West Africa, it is the largest producer with annual production of 3.95 million tons harvested from almost 363,000 ha in 2105/2016 [3,4]. The yield potential of plantain under rain-fed condition is estimated at $38 \mathrm{mt} /$ ha with a current yield of about $11 \mathrm{mt} / \mathrm{ha}[3,5]$.

While marketing structures of fresh plantain fruit are very well established, the utilization of other parts of the plant are practically limited to the use of fresh leaves as animal feed, of green leaves for wrapping food, like Kaakle, or of dried leaves as wrappings for traditional dishes like Kenkey. There are also niches where traditional non-food uses are sometimes practiced. For example, the sap from the pseudostem is used as a dye for the traditional textile industry [6], or plant extracts being used for medicinal purposes, in particular for its blood coagulant properties. Despite all the traditional 
knowledge, other uses widely disappeared in most communities. Especially the use of the fiber-rich parts, like the stalk and pseudostem, lost their importance, which resulted in large quantities of plant residues being left on the fields after harvest.

Although there is high potential of plantain and other fiber-rich plants, the Ghanaian textile industry only processes cotton. Over the past couple of years, the cotton sector seems to fade away due to unauthorized and cheap imported textiles from e.g., China, India, and some African countries, and due to imported second hand clothing from Europe [7,8]. Relying on cotton as the sole raw material for manufacturing textiles and apparel is risky. Cotton grows in the northern part of the country, making transportation difficult, transaction costs high, and available produce often limited [9].

Against the background of such bottlenecks, the concept of a bio-economy with cascading uses, efficient utilization of plant by-products, and interlinkages between different value chains resulting in a value web, appears rather attractive for Ghana, not only for the textile sector, but generally for the whole economy. Focusing again on the increasing demand for natural fiber for textiles, it will be necessary to identify alternative plant-based sources that do not compromise food security. A major untapped potential in Ghana lies in the use of plantain residues as a source for natural fiber.

In contrast to other countries, like Uganda, India, or the Philippines, where banana fiber is already being used for fabrics, paper, etc. [10,11], the abundance of plantains in Ghana remains overseen when it comes to its potential contribution to the development of a sustainable bioeconomy. However, it is unclear which institutional, logistic, or socio-economic structures hinder the use of plantain residues in this context.

Therefore, this study (i) assessed the predominant production structures of plantain, (ii) derived a fiber (textile) focused value web for plantain and cotton, (iii) identified bottlenecks regarding institutional settings, and (iv) discussed a possible pathway to initiate the use of plantain fiber as part of the bioeconomy.

After a short reflection on plantain as a potential source of fiber and the current uses of plantain in Ghana, we describe the underlying conceptual framework that guided this assessment. Subsequently, a reflection on the applied methods and tools are given, and the empirical results are presented. The following discussion of the findings led to the conclusions and some implications for potential starting points to kick-start the development of plantain fiber-based value generation in Ghana. Thus, the results may contribute to an action-oriented follow-up project linking the identified stakeholders and initiating collaborations or a pilot project between local and possibly international stakeholders.

\section{Background and Underlying Concepts}

\subsection{Reflecting on the Bioeconomy}

Historically, biomass has been an intrinsic part of every economy. With the intensive focus on fossil fuels and the importance of the petro-chemical industry, the use of biomass as raw material inputs has lost its importance. Due to the expectation of a "peak-oil" scenario in the mid-21st century, the concept of a bioeconomy, i.e., an economy that is based on renewable biomass, was developed so as to offer a solution. Despite novel oil extraction techniques that allow for new resource exploitation, thus leading to substantial price drops, the strategy remains high on the political agenda, because of its strong contribution to achieving the set of environmental and climate change targets [12].

The concept of the bioeconomy has gained international importance and an increasing number of countries developed bioeconomy strategies. Each national strategy provides a country-specific, systematic framework with the aim to guide the design and development of a sustainable economy that is grounded on sound knowledge and is based on the use of biological and renewable resources. There is no single definition for the term, but at the Global Bioeconomy Summit in 2018 it was defined from a global perspective in rather general terms as: "the knowledge-based production and utilization of biological resources, innovative biological processes and principles to sustainably provide goods and services across all economic sectors" [12] (p. 4). Further, the "sustainable bioeconomy can help 
respond to societal aspirations and needs through its links to several relevant SDGs including poverty reduction, food security, access to water, energy and education, and sustainable innovation, production and consumption" [13] (p. 8).

In the past decade, the use of biomass for non-food proposes strongly affected prices and political debates (e.g., food vs. fuel), and global trade. Its repercussions were observed to be rather dramatic during the economic crisis in 2008/09. Therefore, it is of global interest to use scarce natural resources more efficiently and sustainably. This is particularly relevant when looking at the development of new materials and processes. This implies that an increased use of biomass as an industrial primary material should not happen at the expense of food and nutrition security, the environment, or social dimension [14,15].

The traditional sectors of the bioeconomy are not only linked to agriculture and forestry, but also they include the processing and service industry for both food and non-food materials (e.g., paper, textiles, construction building blocks, chemicals, etc.). In addition, it is required to develop new or optimize existing technologies with bio-based processes, and to more efficiently use available products and industrial applications [12].

Currently, 50 countries have developed national bioeconomy strategies. The targets and pathways to achieve a sustainable economic system differ among the countries, especially because of their different factor conditions. Technologically advanced and land-scarce nations focus more on bio-, nano-, and information technology, whereas countries with high net-biomass-productivity have a comparative advantage in providing primary products that are essential for further processing $[16,17]$. To transform the economic system towards a sustainable bioeconomy, efficiency gains are inevitable. This implies that processing needs to be based on fewer inputs, with less negative externalities (e.g., environmental pollution and greenhouse gas emissions). Furthermore, the holistic use of plants and the cascading use and/or re-use of products and commodities during their lifespan are relevant [15]. On the production side, indigenous and locally adapted crops may play an important role, as they often achieve good yields without the need of high external inputs. Examples in recent literature address the case of sugarcane in Brazil [18] and the role of cassava in Ghana [19].

Regarding the Ghanaian bioeconomy, plantain represents an optimal crop with untapped potential for various reasons. Firstly, plantain is a locally grown crop, which is well established and adapted to the local pedo-climatic conditions. Secondly, it is in the first place a food crop of which less than half of the plant's total biomass is harvested. The remaining crop parts (leaves, pseudostem, roots) are very rarely used leaving an unexploited potential. Thirdly, it is competitive in its resource use as compared to, for example, cotton. Furthermore, due to its extensive biomass production and its large number of traditionally known uses, it has a strong potential to be easily accepted by the local population as a sustainable biomass source for the bioeconomy. Picking fiber as the focus of this study, a closer look reveals that plantain may prove superior to other fiber crops, like cotton, which is grown under sub-optimal environmental conditions demanding a lot of water and external inputs. It may be expected that fiber sourced from plantain residues comply with the overall aspirations of the bioeconomy by fulfilling the aims of a sustainably grown, processed, and manufactured end product.

Natural fibers find application in various sectors in the industry. For example, in Brazil, they are used to reinforce recycled polypropylene to strengthen the material and are expected to replace glass fibers and mineral fillers in the plastic industry [20]. Another example is the textile and clothing sector with its growing demand over the past decades. Regarding the different physical properties of different natural fibers, it may be required to refine the raw material mechanically or with certain chemicals or enzymes. Next to clothing, other promising uses of fiber include non-woven technical textiles, composite material in the automotive sector, components in building materials, like light-weight construction materials, composite in polymers, or molded pulp applications. 


\subsection{Theoretical Basis}

To better understand how plantain residues, especially the underutilized pseudostems, can serve as an industrial raw material in the emerging bio-economy of Ghana, we combine three methodological approaches in the conceptual framework. First, the biomass-based value web extends the traditional idea of a more linear value chain through a systems approach. When looking at product flow, information flow, or the value generation in a multi-dimensional way, linkages, synergies, and leakages between different value chains may be identified, addressed, and consequently may lead to productivity increases of the whole system or network [15,21]. A crucial part of the web approach comprises (i) the idea of a full use of biomass, e.g., crops, including so far disposed of plant parts and (ii) the aim of cascading use of products, which may be recycling or upcycling, too. Hence, tapping into plantain residues to open new value generation strategies provides a good example of a value web view.

As for the complexity of the value web with interwoven value chains, a functioning system will require different factor conditions and structures to be in place. As a second method, the Porter's diamond model [22] is adapted so as to identify determinants and preconditions that are needed for a sustainable and productive bio-economy. In detail, six elements are included: (i) factor conditions referring to the available resources, (ii) demand conditions reflecting marketing opportunities, (iii) related and supporting industries providing physical, technical, or intellectual inputs, (iv) firm strategy, structure, and rivalry, i.e., the way national companies are set up and operated, (v) government determining the institutional and political setting, and (vi) chances or shocks that may influence the development. All elements are interlinked, influence each other, and may also be practically linked in one or more ways to the biomass-based value web idea.

The third concept applied is the National Innovation System (NIS). It allows for assessing which key elements ( $\sim$ stakeholders) and which relationships ( linkages) exist and they are important for generating and diffusing new knowledge and innovations that are useful for the economy [23]. Established and functioning interactions within and between science, technology, economy, policy, and culture combined with complementarities between regions and the whole country are needed for national development [24]. Combining and linking these three theoretical models allows us to identify key stakeholders and to interpret their role in fostering the inclusion of plantain fiber into the value web and bioeconomy.

\section{Data and Methods}

This article originates from a demand-driven approach to explore the potential of national or international demand for example biomass products for industrial purposes that can be produced under comparative advantages in Africa. Plantain fiber was identified as a high potential commodity for a sustainable textile industry. Against this background, the supply side structures in Ghana, as well as the gaps, challenges, and opportunities in the value web are assessed in this study.

\subsection{Research Design}

In order to address the first objective of describing predominant plantain production structures, a thorough literature review was conducted. During on-site fieldwork, the preliminary findings where confirmed by experts and validated in several field visits. The review also allowed for identifying research institutes and experts in the Ghanaian plantain context, thereby providing the starting point for addressing the second objective, i.e., determining the plantain-cotton-value web. In a first step, key informants from the Council for Scientific and Industrial Research (CSIR), particularly the Food Research Institute (CSIR-FRI), and the Crops Research Institute (CSIR-CRI), where interviewed and asked to name relevant stakeholders in the plantain value chain. Similar to a snowball-sampling approach, the identified stakeholders, e.g., GRATIS foundation, ministries, farmer groups, etc. were 
visited, interviewed, and asked to suggest additional respondents. This design enabled a constantly growing picture of the plantain-cotton network.

Fieldwork and data collection took place during April and May, 2016. Next to the interviews, farmers' fields, weaving workshops, and textile factories were visited. In the case of plantain, the sites visited are located in Brong-Ahafo, Ashanti, and Eastern Regions. These three regions are located in an agro-ecological zone favorable for plantain, and account for $79 \%$ of total plantain production in Ghana [25]. For logistic reasons, the field visits and group discussions were organized along major roads connecting agricultural markets in Techiman, Sunyami, Kumasi, Nyambekyere, Ofinso, and Akosombo. In the case of cotton, the Volta region hosts the few processing centers in the country and it was therefore selected. In addition, it was possible to visit two banana plantations and get an idea of large-scale, export-oriented producers.

Complementing the interviews, focus group discussions and literature review with drawing the plantain value-web enabled the assessment of the current stage and potential future development, like the cascading utilizations of the plantain biomass for food and non-food purposes.

\subsection{Research Tools}

In order to visualize the actors and linkages in the plantain and cotton value web, a participatory tool that is known as Net-Map was applied. Developed by Schiffer [26], this instrument starts with informing the respondent or responding focus group about the purpose of the research and explaining how the Net-Map exercise works, in order to describe and understand the linkages between actors in the crop sectors. Using a blank Din A2 sheet of paper, the main questions guiding through the exercise for the plantain-cotton sector were:

1. 'Who is involved in the plantain/cotton sector?' Key persons and/or respondent groups were asked to identify stakeholders in the production, marketing, processing, and consumption of plantain (use of cotton), as well as other actors or institutions that may play a role in supporting or otherwise influencing the sector. The actors were categorized by type (e.g., producer, processor, private or public institution, etc.) and noted down on the blank sheet.

2. 'How are the actors linked?/Which linkages exist between the actors?' The interviewees were asked to identify and describe existing (and non-existing) linkages between the different actors. The type of linkage was color-coded and differentiated into (i) knowledge and information flows and (ii) product flows reflecting actual business connections. When drawing the linkages on the paper sheet, the direction of interaction was indicated by one- and double-sided arrows.

3. 'How influential are the actors with respect to initiating and/or developing the use of plantain for fiber?' The interviewees were asked to assess, from their perspective, which role different actors play when it comes to establishing a plantain based fiber value web. Using flat washers, the level of importance or influence could be indicated by allocating different numbers to different actors.

To gather additional information on bottlenecks, challenges, opportunities, etc., the individual network maps were discussed with the respective respondent or group. This allowed for gaining an in-depth understanding about the interviewees' reasoning of why some players are more important than others, how different linkages work (or not work), if there is a chance for plantain fiber, and how they perceive the sector.

With the intention of getting a full picture, the separate plantain Net-Maps were combined into a final map. Acknowledging the biomass-based value web idea and considering that plantain fiber for the textile industry is considered, the map was extended to include national actors from the cotton fiber processing sector. This amendment was possible by including key person interviews of and factory/workshop visits to textile companies and local, traditional weavers.

Furthermore, the mapping exercise was supplemented by common qualitative research tools, including in-depth personal interviews with key persons and experts, and focus group discussions with different stakeholders. Overall, in-depth interviews were carried out with 24 persons (nine key experts), 
six focus group discussions were organized, and six detailed Net-Maps were drawn. Stakeholders interviewed included plantain farmers, market actors (transporters, traders), scientists at research institutes, and other institutions from the private and public sector. Details are listed in Table A1 in the Appendix A.

Data quality was ensured through the combination of the different methods applied, which guaranteed the triangulation of the results. In-depth interviews follow a pre-defined structure and purpose, and thus differ from a conventional exchange of perceptions, thereby allowing the collection of rich data [26].

\section{Results}

With plantain at the focus of this study, this section starts with a brief overview of the main plantain production systems that are currently found in Ghana. It then maps out and discusses the links between different institutional structures that are relevant for integrating plantain into the bioeconomy. Connecting the plantain knowledge and information flows, plantain product flows, and cotton product flows allows for the illustration of a potential plantain-cotton value web for Ghana. The developed figures were generated based on information collected with participatory tools and are supplemented by the findings of in-depth interviews.

\subsection{Plantain Production Structures and Value Web}

About $90 \%$ of plantains are grown by smallholder farmers. Of the different farming systems that are described in the literature for West Africa [27], three intercropping strategies are predominantly found in Ghana. Most important is the cocoa-plantain combination. Here, a farmer starts with cultivating plantain as a nurse crop (locally referred to as pioneer crop) providing shade for young cocoa plants. During the initial first three years when the cocoa matures, plantain provides food for home consumption or sale. Once the cocoa is established, plantain is gradually phased out or moved to the borders of the fields $[25,28]$. In fact, this strategy is heavily supported by a project of the COCOBOD (Ghana Cocoa Board) which aims at providing ten million cocoa seedlings to farmers [29]. The support from the COCOBOD not only includes information on good agronomic practices that are related to cocoa, but also the provision of seedlings to the participating farmers. In general, the project is seen as very beneficial by farmers. They reported to be particularly interested in getting involved in cash crops, like cocoa, even more so when seedlings and equipment are being provided. One drawback appears to be the focus areas. Farmers living too far from the cocoa nurseries were unhappy about an unfair support. Another critical point may be agronomic practices. Several field visits to cocoa-plantations revealed that in a lot of cases, cocoa pods are not harvested properly, left rotting on the stem, or not used for processing (drying, etc.). Farmers mentioned that this lack of interest and commitment is due to the limited access to markets with good cocoa-prices.

The other two production systems are more oriented towards producing (home-)consumption crops. One cropping system is intercropping plantain with cocoyam (taro). According to farmers' statements, this mix provides them with an additional crop that can either be used by themselves in the household, or be sold on the market if there is surplus available or cash income required. From a food security perspective, diversifying the diet by adding roots and tubers to daily meals should have a particularly positive effect on nutritional aspects. To prove this empirically, further studies will be helpful. Cash-crop farmers also stated that the crop mix is often chosen as an alternative to a single nurse crop for cocoa. The advantage here is that, during the early years, two types of food crops can be harvested. Relying on a more diverse crop portfolio is seen as a means of reducing risk and, at the same time, increasing land productivity.

The third cropping system that is regularly encountered is intercropping plantain with cassava. This mix also draws its importance from very popular food preferences, i.e., Fufu. Fufu is a national dish made by mashing plantain with cassava. For many rural farmers this is a main staple food consumed on daily basis. However, also in more urban areas, from small food shacks to high-level 
restaurants, this traditional dish is part of the menu. Not surprisingly, several research activities, small and medium enterprises, and large players in the food processing industry invest in developing and setting up processing lines to produce plantain and cassava flour, so as to increase shelf-life of the perishable fruits and roots, respectively. Packaged flour ready for use is especially relevant for urban areas, like Accra, where supermarkets are becoming more and more important as a source for groceries.

The map of the plantain biomass web illustrated in Figure 1 identifies the cascading uses of plantain biomass in Ghana and potential other products that are relevant for the bioeconomy.

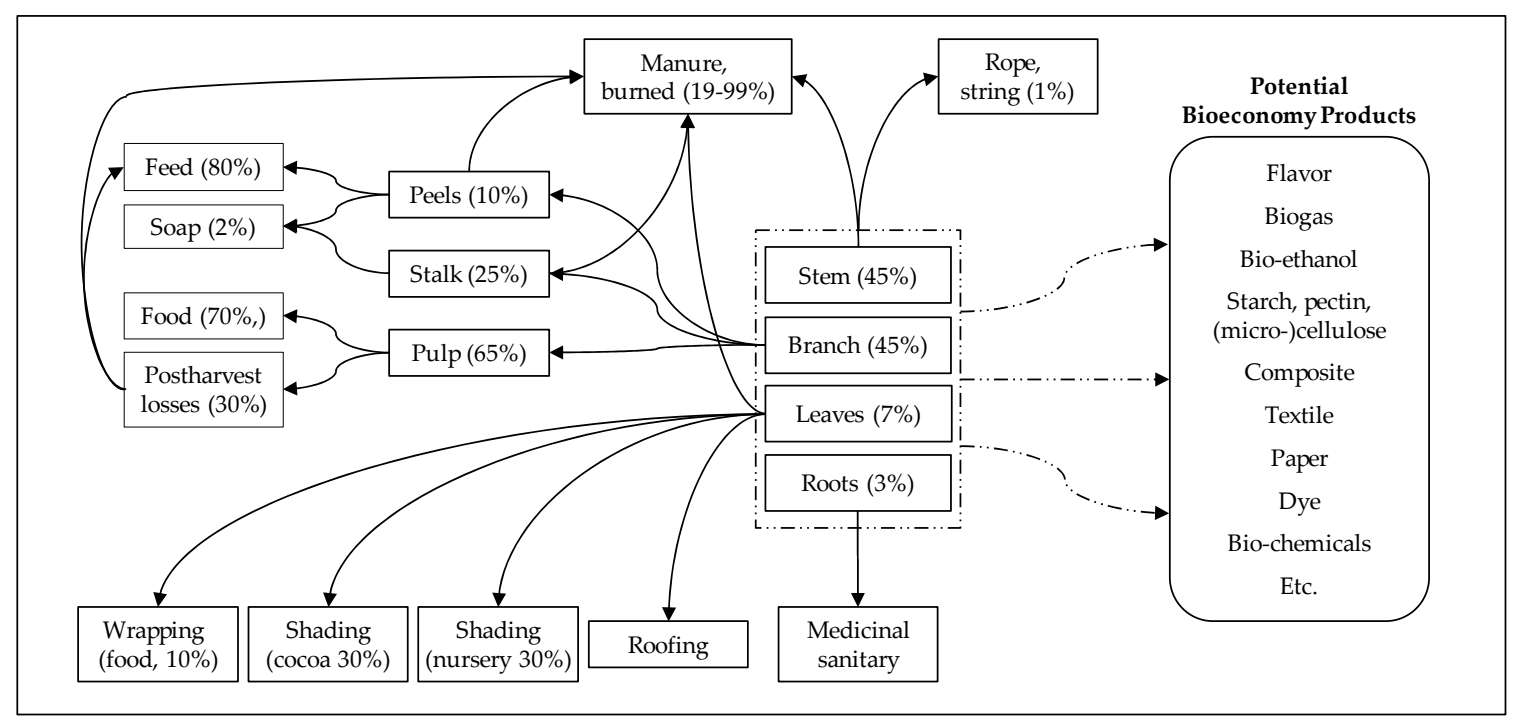

Figure 1. Biomass flows in the plantain value web; Source: own data, additions [30,31]; percentages are estimates based on expert interviews and literature [32].

\subsection{Mapping the Plantain-Cotton Biomass Web}

Drawing on the theoretical considerations of a biomass-based value web as a cornerstone of a sustainable bioeconomy, the plantain and cotton fiber related institutional structures and networks that are assessed in this paper include three components. Firstly, knowledge and information flows relevant for plantain (and cotton) production, processing, and marketing provide the foundation for an up-to-date technological and innovative development processes. Secondly, the plantain product flow identifies currently produced and traded products, as well as the respective stakeholders involved. Thirdly, when assessing the potential of using plantain pseudostem residues for fiber production, it seems essential to also understand the cotton product flows, as the main natural fiber currently used.

\subsubsection{Plantain Knowledge Flows}

Starting with the national innovation system perspective, Figure 2 shows stakeholders, linkages, and flows of knowledge and information about plantain production, use, and processing. Relevant in Ghana are actors from research, politics, extension services, and non-governmental organizations (NGOs). In general, two types of information are generated and/or provided. Smallholder producers are supported with suggestions on how to improve production practices targeting an increased fruit yield. Involved are the government extension service through the Ministry of Food and Agriculture (MoFA), the Council for Scientific and Industrial Research-Crops Research Institute (CSIR-CRI), NGOs, and to some extent other research institutions, including universities. Offered are e.g., group trainings or field visits with individual advice on topics like plantain propagation, greenhouse multiplication, and general agronomic techniques. When considering knowledge generation, the most active are universities and the CSIR-CRI, which may also collaborate, and in some cases, exchange information. Regarding food processing, the CSIR-Food Research Institute (CSIR-FRI) seems to be the driving force in developing and introducing processed plantain products. By providing technical advice to private, 
mainly large enterprises, the mandate is to bring Fufu powder, plantain chips, and other products with long shelf life into supermarkets so as to improve supply and access to key food commodities to the urban population.

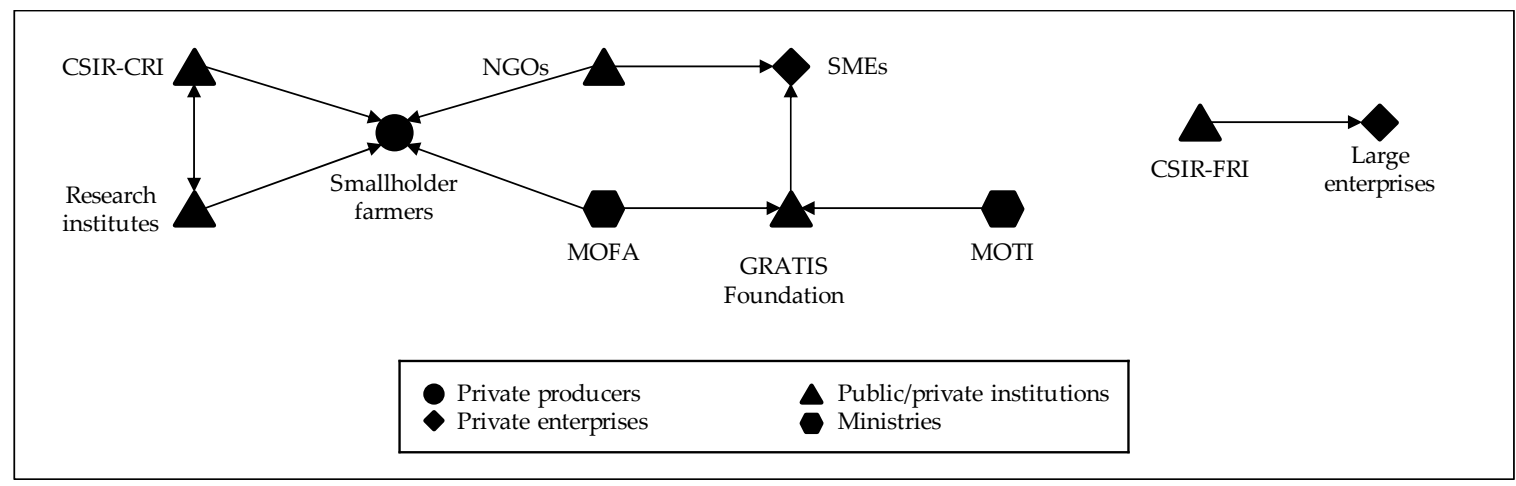

Figure 2. Visualization of plantain related information and knowledge flows; Source: own data.

Special attention should be given to the GRATIS Foundation of Ghana. Initiated as a 'spinoff' of a project carried out by the Ministry for Trade and Industry (MOTI), the goal of the foundation is to provide a platform for the structured vocational training of young adults to be (agricultural) mechanics that are capable of opening their own workshop, and to produce and market technical equipment, like cassava grinders, etc. The network of GRATIS-workshops is supported by two ministries and it frequently collaborates with small and medium enterprises in need of machinery equipment. What appears to be missing is a direct link with the research side (CSIR institutes, universities), thus making it likely that innovations and new technologies face a time lag regarding dissemination.

\subsubsection{Plantain Product Flows}

At the focal point of a plantain fiber value web is, of course, plantain production and product flow. As indicated in the short literature reflection and observed during fieldwork data collection, there is currently hardly any use of plantain fiber in Ghana. Although traditional uses, like ropes, sanitary pads, or medicinal purposes, are reported, it seems that its actual use widely disappeared among farmers, traders, and other people. In contrast to several other countries, Ghana appears to be unaware of the potential of plantain pseudostems as a natural fiber source for national and international processing including e.g., the textile industry. Thus, Figure 3 rather visualizes the current flows of fresh fruits and leaves. Yet, the stakeholders could easily pick up steps, like bulking, transportation, or marketing of plantain fiber or fiber bundles, and therefore may serve as a blueprint when making use of the whole plantain biomass.

Two producer structures were identified during fieldwork: Small-scale plantain production by smallholder farmers in the Southern regions of Ghana; and large export-oriented plantations of banana in the South-Eastern regions. Although this paper focuses on plantain, banana or generally all Musa species may have comparable potentials as fiber sources. Especially, large-scale plantation enterprises can be assumed to have logistics, management, bulk production capacities, etc. that may be expanded to also consider fiber production.

Despite some bottlenecks in marketing [33], the marketing channels for plantain fruit are very well established. Fruit bunches find their way to consumers via traders at the village level, market women, aggregators and wholesalers, and retailers. Particularly important for markets in Ghana are female trader groups that are headed by 'market queens' who manage the marketing. While older research claims them to control prices and market access [34,35], more recent findings suggest that they are essential for the value chains as types of collective action and credit groups $[36,37]$. 


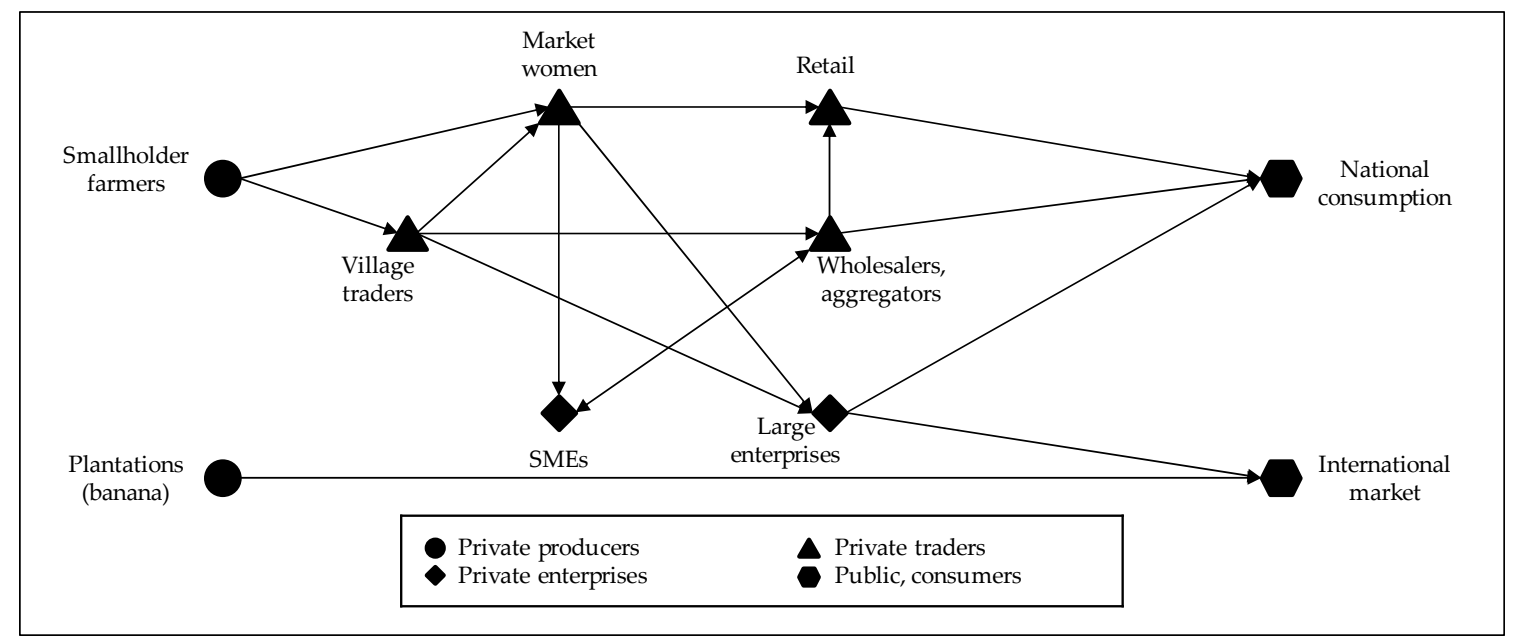

Figure 3. Visualization of plantain product flow; Source: own data.

Small, medium, and large enterprises processing plantain fruits or using leaves as wrappings when preparing food dishes either get their raw material from local village traders, or from market women who usually can provide larger quantities. Regarding plantain, constraints mentioned frequently are the perishable nature of the fruit as well as its bulkiness. It seems difficult to optimize transportation logistics and match demand with available produce when many traders, aggregators, and wholesalers compete. Especially the seasonality of plantain availability leads to price fluctuation.

Plantain fiber would be a new commodity added to the plantain product flows. From a generic value chain perspective, fiber bundles are extracted, dried, and baled close to its cultivation area. This implies that either producers, producer groups, or private start-ups are needed to enter the network between the initial production and local village traders. As farmer groups already exist and Ghana's business environment appears very vibrant, this bottleneck may be addressed if appropriate support measures are put into place. The further downstream transportation and marketing could easily be taken over by the established traders who in many cases deal with several different commodities. In order to use the fibers, for example, in the textile industry, further processing steps, like spinning, weaving, or apparel manufacturing may be carried out by other companies that are yet to be established. Especially, if the finally targeted product is supposed to show properties like cotton, more complex processing like chemical or enzymatic treatment will be needed to reduce the high stiffness of banana fiber. A recent study discusses the mechanical properties of banana and other fibers, and shows that it is possible to produce a textile grade of banana fibers [38]. The study also discusses options of mixing banana with other natural fibers, like wool, flax, hemp, or cotton. Currently, banana based rayon, often referred to as banana-silk, is already widely available on the market as yarn, fabric, clothing, or other goods, and is offered by e.g., Frabjous Fibers (USA), ZS Fabrics (USA, India), or Green Banana Paper (Micronesia). Considering merely the textile sector is falling short of the many other potential uses of plantain residues or by-products, some requiring sophisticated technologies, others low-tech solutions.

\subsubsection{Cotton Product Flows}

Emphasizing and concentrating on the textile and clothing sector as a continuously growing market worldwide, the national production and processing of cotton might appear as a key sector in the Ghanaian bioeconomy. Figure 4 presents the cotton stakeholder map for Ghana. National cotton production takes place in the Guinea Savanna zone in the northern part of the country. The produce may pass through village traders and wholesalers to the few national large-scale processing factories that are located in the Volta region. Ginning, spinning, weaving, and finishing fabrics all takes place in the factories. The final steps in manufacturing textile apparel generally takes place in small and medium enterprises before entering the retail market. The in-depth interviews with textile companies 
revealed that the more important source of cotton is the import from China. The input is said to be cheaper, more accessible, and reliable due to the closer location to the harbor, more abundant, and of similar quality to the national or regional supply. The real challenge, however, was mentioned to be the cheap imported clothing that gradually displaces nationally produced apparel. There seems to be double the burden of depending on imports of cotton bales (mainly from China) for further processing, and having to compete with the imported end products. Therefore, the interviewed managers of the textile factories were keen on learning about alternative natural fibers that may prove competitive in the near future.

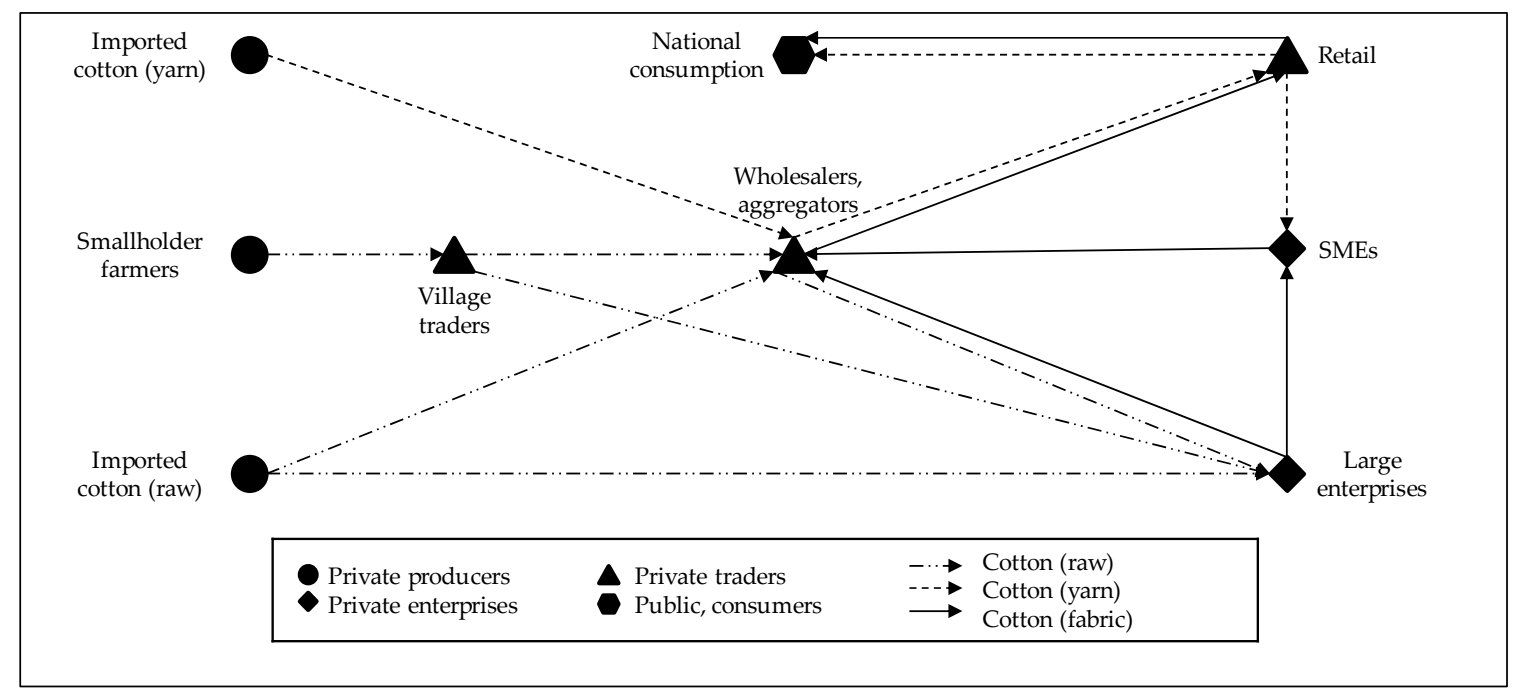

Figure 4. Visualization of cotton product flow (simplified); Source: own data.

An exception in the Ghanaian textile sector can be found in Kente cloth and fashion. Kente are traditional, colorful clothing carrying different meanings and are worn at special occasions. Using hand operated looms, small-scale weavers produce the required number of cloth-pieces (each ca. $10 \times 10 \mathrm{~cm}$ to $20 \times 20 \mathrm{~cm}$ ), which then are sewn together to get the whole expressive garment. The employment arrangements among the interviewed weavers varies: self-employment, working in loose groups, working as part of an association, or being employed. However, all of these use similar production techniques and rely on the same input namely imported cotton yarn and/or thread purchased on the local market. In the end, they claimed not to really care about the original source of fiber used for the yarn, if the required colors are available and weaving properties are guaranteed.

\subsubsection{Plantain-Cotton Value Web}

In order to fully understand a natural fiber value-web considering both plantain and cotton in Ghana, the information and knowledge network and the two product flow networks are combined in a single Net-Map, as shown in Figure 5. Most relevant from the value-web perspective are those stakeholders being active in different networks, hence forming the linkages between the systems.

Starting with crop production, smallholder farmers are the stakeholder in common. As cotton and plantain grow in different agro-ecological zones, i.e., cotton in the northern part, plantain in the central and southern parts of Ghana, there will not be much overlap, competition, or synergies to be expected. However, with the public extension service as the main source of agronomic advice, there are likely to be similar bottlenecks, like coverage and frequency of support given. During focus group discussions with plantain farmers, farmer groups, and extension officers the lack of enough trained staff, and targeted (re-)training were highlighted several times. In addition, information about new agricultural technologies was reported to not reach extension officers. Innovations only find their way quickly to farmers if they collaborate with research projects. 


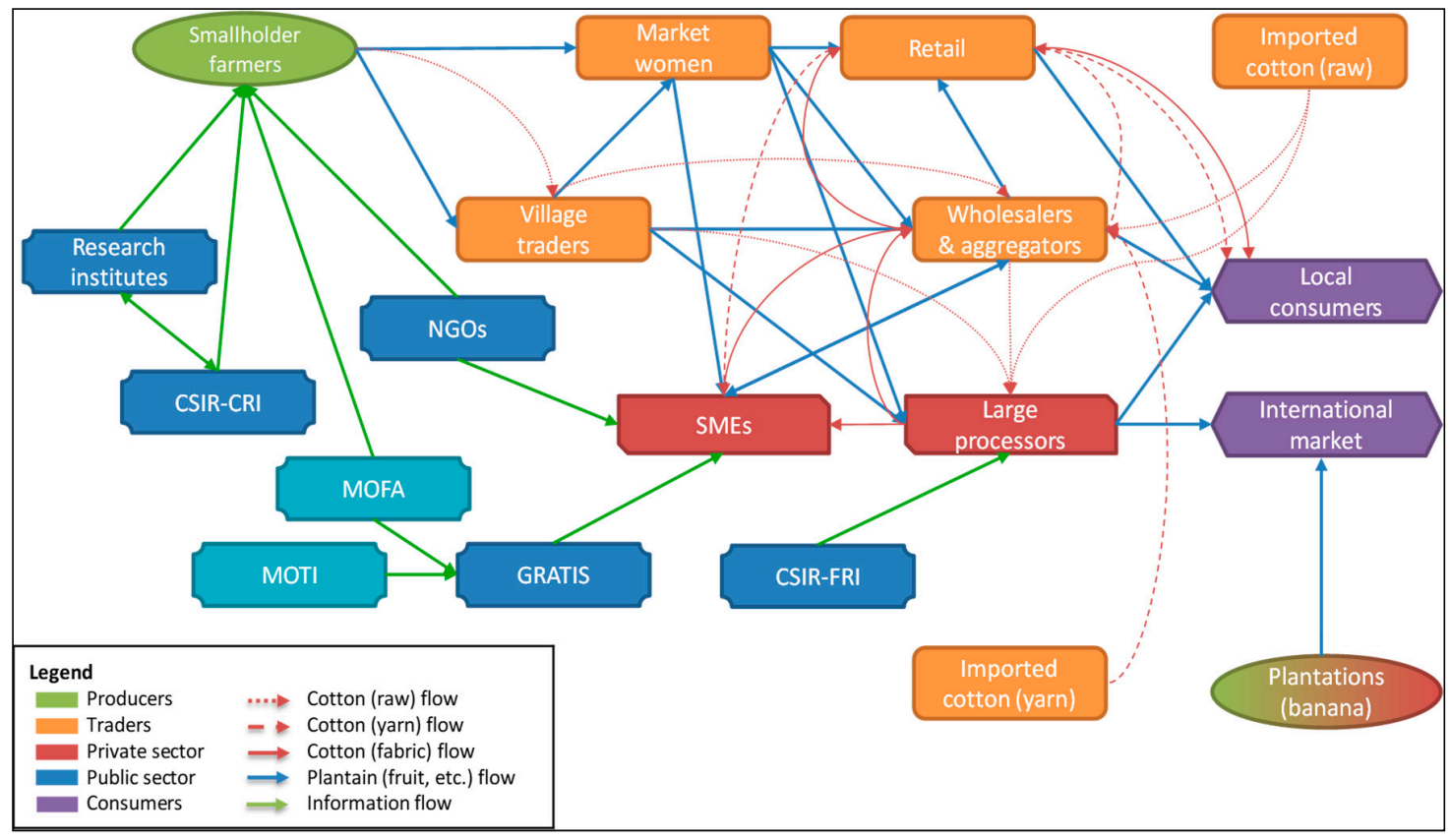

Figure 5. Plantain-cotton value web in Ghana; Note: Currently, only plantain fruit and leaves are used commercially; Source: own data.

Regarding processing, the key to a sustainable downstream value generation based on plantain fiber involves small and medium enterprises (SMEs) or large processors. Currently, both types of private sector actors handle plantain fruit. SMEs are backed by NGOs, and, more importantly, the GRATIS foundation. Each of these knowledge support agents may also expand their field of activity to provide information and technical know-how necessary to establish plantain fiber extraction. The GRATIS workshops may even be involved in designing or adapting suitable equipment for fiber extraction. If financing issues can be overcome, new SMEs may develop taking over processing steps, like ginning, spinning, weaving, and further processing, thereby creating new jobs and opportunities. The large-scale textile companies currently do not operate at full capacity. Thus, with some amendments to processing lines, they could evolve into the most important domestic demand side players utilizing both cotton raw material, plantain fiber raw material, and in the long run possibly other natural fiber sources, like e.g., pineapple, bamboo, rattan, etc.

\section{Discussion}

This section mainly discusses the empirical findings concerning the institutional structure of plantain with respect to the elements of the Porter model and the National Innovation System. The discourse allows for drawing implications regarding the potential of plantain fiber in Ghana and to develop a possible pathway for initiating fiber use of plantain residues.

\subsection{The Plantain Biomass Web}

Plantain is one of many species of the Musa genus grown worldwide. Whether as sweet fruits or as a staple food with high starch content, the fruit is generally the main part of economic interest. In Ghana, the number of smallholder farming households cultivating and relying on plantain for home consumption and income generation is estimated to be more than 400,000 families [25]. Assuming that the biomass of an average plantain plant is distributed to the bunch branch (45\% of the biomass), stem $(45 \%)$, leaves $(7 \%)$, and roots $(3 \%)$, and only the stem and leaves to be regularly used, there is a huge gap in sustainably using the full plant potential in the sense of a cascading and whole plant use envisaged in a functioning bioeconomy. 
While the use of by-products is widely applied and established in many other parts of the world, the systematic use and value generation through plantain residue processing is very rare in Africa in general. An exception that was identified in this research is an initiative to start utilizing plantain in Uganda through an innovation platform [11], but the technology and knowledge transfer seems to be stuck in the country. At least there is no evidence that any collaboration with West-African partners were attempted or conducted. Potential uses of banana by-products reported in the literature are manifold (see Section 4.1, Figure 1, [30,31]) and could easily be adapted to any Musa species. Depending on different processing techniques, end products may serve as food or as non-food commodities. Looking at the pseudostem, different extraction methods exist to yield fiber and pulp to be used in textiles, paper, or as a composite. Known and established extraction methods include mechanical, chemical, and enzymatic treatment. Though still at a research and development stage, steam explosion may prove as an interesting and effective alternative in the future. In the Philippines, Indonesia, India, and other South-East Asian countries, the fiber of different Musa species, e.g., Musa textilis, is already being used for e.g., teabags, ropes, sacks, fabrics, and in some cases also textiles for clothing. In many of these countries, the production and demand structures are well established. Both knowledge and technical equipment, like specific machinery required to extract and process raw fiber from banana pseudostems are available.

\subsection{Factor Conditions}

From a production perspective, two possible strategies stick out. First, the abundant plantain and its current neglect of residue use theoretically may serve as a sufficiently large source of available resources. The crucial challenge is overcoming the small-scale production. With thousands of smallholder farmers operating on little land area, a bulking system would need to be put into place so as to be able to gather adequate quantities of raw material. This could be achieved through forming cooperatives, relying on traders and middlemen, or through implementing outgrower schemes with e.g., contract farming. Here, lessons for an optimal contract design in the context of Ghana's bioeconomy may be drawn from recent findings in the cassava sector $[19,39]$.

When considering that the plantain pseudostems contain large shares of water, an efficient and sustainable use implies the extraction of fiber on, or close to, the production site. With the first processing step near to the production sites, the sap and scraps from extraction may be returned as (fluid) fertilizer to the farms.

Regarding transportation and further processing, the well-established and functioning plantain fruit marketing system may be expanded to include the fiber trade as a regular activity. Already now, traders and transporters fill their trucks with a mix of different marketed food and non-food commodities in order to operate at full loading capacity.

As an alternative to relying on smallholder production, a second approach could be the large-scale, export oriented banana plantations. If they become aware of a potential economic benefit, they may add fiber extraction to their production portfolio. The current practice of utilizing all banana residues as green manure so as to maintain nutrients, is not necessarily compromised if only fiber is extracted. The sap and scraps from extraction may yet be returned on the plantations.

\subsection{Demand Conditions}

On a large scale, the international demand for fiber is expected to continue to increase over the next decade, especially in the textile, paper, and pulp/composite industry. On the one hand, this is due to higher consumer preferences for natural resource based products. On the other hand, the availability as well as the market price for alternative natural fibers like cotton plays a role. Focusing on Ghana, cheap cotton imports heavily affected national production in a way that almost all raw material is now imported. This is especially important for the few large-scale textile companies that reported to be willing to become independent of imported cotton. As national and regional raw cotton production cannot meet the demand, they would gladly handle alternatives. The prerequisite, of course, would be 
the physical (e.g., spinning, weaving) and chemical (e.g., dyeing, coloring) properties of such an alternative natural fiber, as well as a competitive price.

Another positive aspect for fostering plantain based fiber production is that these large-scale companies only operate at a fraction of their installed processing capacity. For example, in the interviewed factory about two-thirds of the equipment is not used at the moment. Despite this, if cotton remains economically superior to plantain fiber, there would still be the option of adapting part of the currently vacant equipment to plantain fiber, thereby providing a basis for generating additional marginal return and making the company more profitable overall.

Apart from the large-scale producers, local demand also includes small-scale weavers who currently fully depend on imported yarn. Similar to the factories, they are ready to switch to yarn originating from fiber other than cotton, as long as the handling is not influenced substantially and the price for yarn is not increased.

\subsection{Related and Supporting Industries}

In terms of supportive structures, especially the knowledge and innovation aspect is rather active in Ghana. Several universities, research institutes, and other initiatives particularly consider plantain. Their focus, however, is mostly on propagation, productivity, and fruit processing. Yet, the institutional structures are in place and they could easily broaden the view to include the use of plantain by-products for e.g., extracting natural fiber from plantain pseudostems. While technical knowledge or equipment is currently not available, a technology transfer is possible from e.g., India, or from the African continent (Uganda). Adaptation, lab testing, or field trials so as to develop suitable equipment could be conducted by universities with a technical focus, research institutes, private consulting companies, or the GRATIS Foundation of Ghana. The latter, and possibly other stakeholders, also have the potential for the upscaling and dissemination of know-how through their vocational training programs. Optimizing, producing, and marketing of machinery could also be organized through their workshop network and marketing system.

\subsection{Firm Strategy, Structure, and Rivalry}

From a national perspective, the large-scale textile companies that are located in the Volta region are likely to serve as the cornerstone of processing plantain fiber. They all have productive capacity, but they face different challenges. The currently active enterprise operates at about one-third of the installed production capacity, it is equipped with rather old spinning machinery and weaving looms, and it struggles with efficiency issues and competitiveness with cheap imports from e.g., China. When targeting the European Union (EU) as a potential international trading partner, previous research by the authors showed that companies pay specific attention to aspects like working conditions or labor safety, which may need to be improved to some extent before receiving certain certifications requested for by the customers. To meet such international requirements, it may be necessary to invest in technical, managerial, and other improvements for which investments are likely to be needed.

At the time of fieldwork data collection, the employees of a second textile company were on strike, because the management did not pay them for three to six months. In informal discussions with some workers, they claimed that the whole board and the executive management were not interested or were not able to properly run the factory. Unfortunately, it was not possible to meet with the management staff due to the strikers barricading the entrance to the compound. Again, this hints at the need for managerial improvements for the large-scale processors.

Turning to small-scale weavers, the plantain fiber raw material is not of interest. Especially, the traditional Kente-weavers use hand-operated looms and they only work with yarn that was bought on the market. Although the interviewed weavers reported to be interested in trying other than imported Chinese cotton yarn, they most likely would still choose the cheaper option for manufacturing. This implies that in order to sustainably include plantain fiber in the Ghanaian (fiber) value web, it is most likely inevitable to also initiate the establishment of spinning facilities in the form of e.g., separate 
enterprises or to couple the refining process with the first processing step of extracting raw fibers on or close to the primary production sites. This approach may induce competition, thereby fostering efficiency and (economic) sustainability.

\subsection{Government and Chance}

Considering the high importance of plantain for the Ghanaian farming population as a staple crop to ensure food security and generate income, public interest, activities, and ministerial support mainly focusses around fruit production and processing. Hence, it is not surprising that farmers are supported mainly through the national agricultural extension system. Fostering research and innovations that aim to extend shelf life or to process fruit to e.g., Fufu powder is of relevance. Other key supporting industries that were identified in the network analysis also receive attention. Most prominent is the support of GRATIS as an approach to improve the vocational training of rural and/or peri-urban youth, to strengthen the dissemination of agricultural innovations, like cassava peelers, and to set up a network of workshops across the country. Regarding the use of plantain residues, including the pseudostem, no specific policy could be identified during the fieldwork interviews. It seems that this neglect originates from the lacking awareness of the economic potential of plantain fiber for the Ghanaian bioeconomy, starting with the rural farmers, traders, processors, and the retail market.

\subsection{Potential Pathway for Utilising Plantain Fiber}

Over the past decades it seems that the traditional knowledge and uses of plantain residues is being forgotten. May it be medical uses of roots or using the pseudostem fibers for rope, string, or sanitary pads, as reported by older interviewees. In order to reignite a whole plant biomass use in an efficient and sustainable manner, the first steps could include fiber extraction. Figure 6 presents how the current fruit-oriented value chain could be expanded to include the use of fiber as a step to a biomass web. Required is the collection of residues from the fields. I.e. the pseudostems need to be collected and processed close to the fields to avoid the transportation of unnecessary weight, i.e., nutrient rich water that can be returned to the field as manure. The raw fiber material can be bundled, undergo mechanical, chemical, or enzymatic treatment so as to reach textile component production (yarn, thread, or fabric), before reaching end products (apparel, home furnishings, or components to other end products), and marketing.

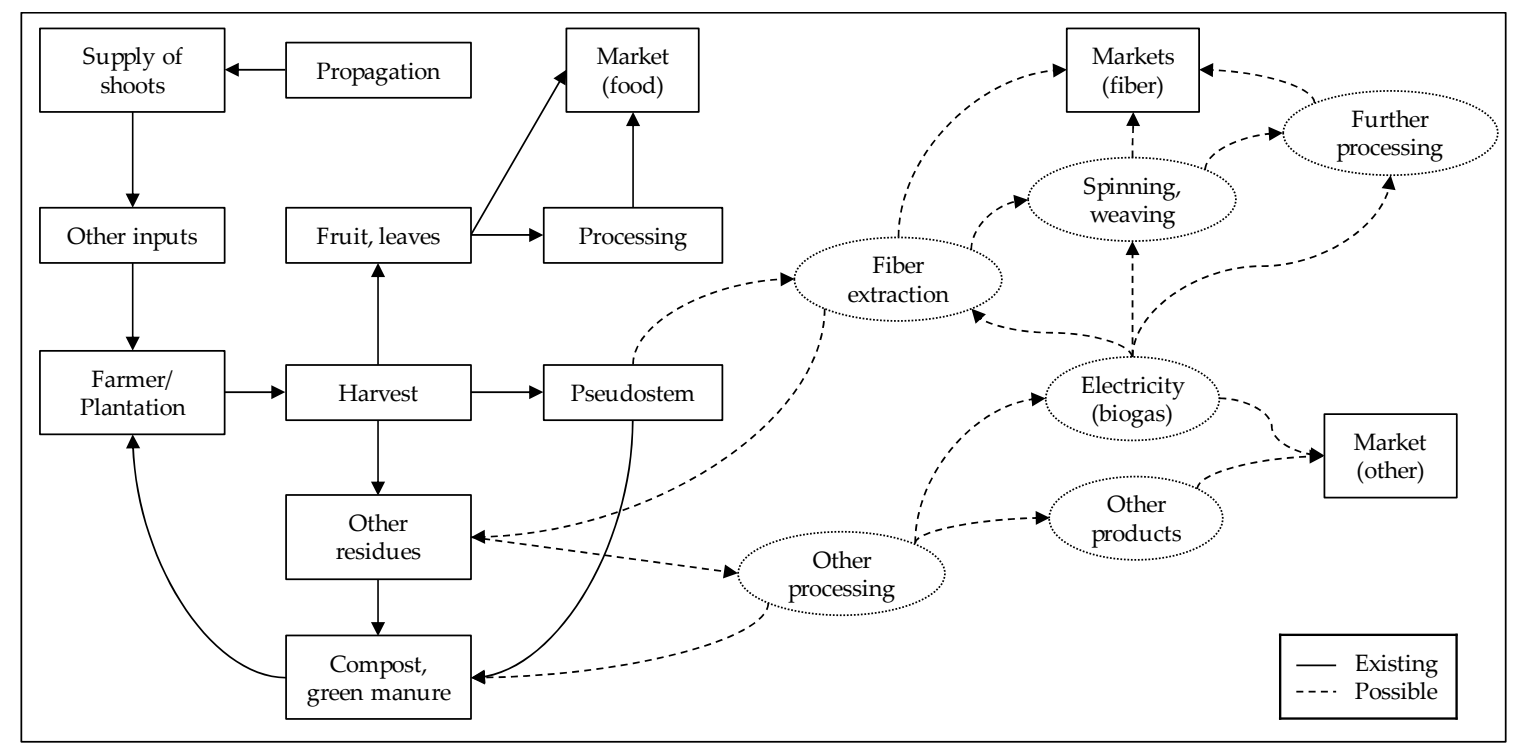

Figure 6. Potential expansion of the plantain value chain to include fiber utilization in a value web; Source: own illustration. 
Residues from the fiber extraction process that are not going directly back to the field may be used in other processing lines. For example, the waste could be used as feedstock for (small-scale) biogas production, which in turn could be used for electricity generation, hence linked back to extraction. Depending on other organic waste that could be added as feedstock and the pursued biogas strategy, other uses are easily possible. Low-cost small-scale biogas reactors may serve as a source of energy at the household level; larger installation may be more market-focused.

In any case, the most critical step is likely to be the bulking of sufficient raw fiber bundles, so as to make it economically viable to establish further processing lines. If it is possible to organize the small-scale plantain producers and to overcome this bottleneck, utilizing plantain based fiber may be a promising addition to the Ghanaian bioeconomy. Drawing from the experience with other crops and/or products, suitable approaches may include the formation of cooperatives who also take charge of extracting fibers near to the production sites, outgrower-schemes with contracted plantain farmers, coupling plantain fiber initiatives with the cocoa-promotion-program, or large-scale banana plantations expanding their portfolio by including fiber production. In this context, looking into the experience made in other countries, identifying existing machinery and equipment, piloting fiber extraction in Ghana, and assessing technology transfer appear as useful, action-oriented follow-up research directions.

\section{Conclusions and Implications}

In this article, we investigate the institutional environment of the Ghanaian plantain sector and assess the potential to tap the abundant, but so far underutilized, plantain residues as a source for natural fibers. The objectives of the research were to (i) describe predominant production structures, (ii) derive a stakeholder network map, respectively, the value web, so as to identify challenges and opportunities regarding institutional settings, and (iii) discussing how this supply side may be linked to the national market or the international demand side.

Required information on the plantain production structure and the connected institutional network system were mainly gathered through qualitative research techniques, including key person interviews, focus-group discussions, and the participatory Net-Map tool. When considering the theoretical concept of a biomass-based value web, the cotton value chain was incorporated in the value web. Currently, cotton is the main source for natural fiber processing actors in the textile sector, who were included as national users of natural fiber. Drawing on the National Innovation System and Porter's diamond model, the potential of initiating and developing a plantain fiber based value generation was discussed.

Starting with the description of plantain production structures, we found three predominant intercropping systems: plantain with cassava as a mixed food production, and both plantain or plantain with cocoyam (taro) as pioneer crops for cocoa in early years. The latter is heavily supported by public initiatives. The majority ( $90 \%$ ) of plantain is grown by smallholder farmers. In the research area, i.e., the main plantain producing regions, there are farmer groups or associations that may play a role in bulking produce. Regarding the production, marketing, and processing of fresh plantain, the value chain is very well established. A notable utilization of plantain for fiber or other purposes is not present in Ghana.

Assessing the institutional map and value web revealed that, from a National Innovation System perspective, the required institutions are all available and operating in the country. In detail, this means that specific plantain focused research, extension, and support actors are already intensively in contact and collaborating with smallholder farmers. In addition, general technical knowledge is available and the adaptation of foreign fiber extraction machinery could be carried out easily by e.g., the GRATIS Foundation of Ghana (a 'spinoff' of a project of the Ministry of Trade and Industry). On the processing side, i.e., spinning raw fiber to yarn, the private sector only has experience with cotton, but it shows willingness to experiment with other natural fibers to become more independent of imported raw material and to optimize capacity utilization. 
In a broader sense, the findings of this research indicate that Ghana has got the infrastructure and institutional structures that would allow for developing a sustainable commercial use of plantain residues for fiber. What is needed, however, is (re-)discovering and acknowledging the use of plantain residues as a valuable resource, especially by public support institutions, like the agricultural ministry and its extension system. Combining technology transfer and the adaptation of equipment from e.g., India or Uganda with fostering knowledge about plantain's fiber potential appears to be a promising first step to kick-start a new branch in the Ghanaian value web and bioeconomy. Particularly useful would be further action oriented research, like e.g., developing appropriate equipment and a pilot project involving all stakeholders from (plant) fiber to fabric.

Author Contributions: Conceptualization, T.K.L., M.H.; Methodology, T.K.L.; Investigation, all authors; Writing —original draft preparation, T.K.L.; writing—review and editing, all authors.

Funding: This research was funded by the German Federal Ministry of Education and Research (BMBF) within the framework of the GlobE-Research for the Global Food Supply program. It is part of the collaborative project "Improving food security in Africa through increased system productivity of biomass-based value webs." (BiomassWeb); Grant No. 031A258C.

Acknowledgments: The authors are thankful for the assistance of Solomon Darkey during fieldwork activities and to Michael Kwaku (INBAR, Ghana) for the logistical support.

Conflicts of Interest: The authors declare no conflict of interest.

\section{Appendix A}

Table A1. Overview of expert and focus group interviews.

\begin{tabular}{ccccc}
\hline Stakeholder Category & Field Visits & Net-Maps & Interviews & Focus Group Discussions \\
\hline Farmers & 3 & 3 & 3 & 3 \\
Plantation & 2 & & 2 & \\
Market actors & 2 & & 6 & \\
GRATIS foundation & 1 & 1 & 1 & 2 \\
Cocobod & 1 & 1 & 1 & \\
MoFA/government & 2 & & 7 & 1 \\
Textile SMEs & 2 & 1 & 2 & \\
Textile factory & & 1 & \\
Research institutes & & 1 & \\
\hline
\end{tabular}

Note: Field visits include visits to agricultural fields, markets, workshops, and factories.

\section{References}

1. Dzomeku, B.M.; Dankyi, A.A.; Darkey, S.K. Socioeconomic Importance of Plantain Cultivation in Ghana. J. Anim. Plant Sci. 2011, 21, 269-273.

2. Dankyi, A.A.; Dzomeku, B.M.; Anno-Nyako, F.O.; Adu-Appiah, A.; Antwi, G. Plantain Production Practices in the Ashanti, Brong-Ahafo and Eastern Regions of Ghana. Asian J. Agric. Res. 2007, 1, 1-9. [CrossRef]

3. Ministry of Food and Agriculture. Agriculture in Ghana. Facts and Figures, 2015; Ministry of Food and Agriculture Statistics, Research and Information Directorate (SRID): Accra, Ghana, 2016.

4. FAOSTAT. Available online: http://www.fao.org/faostat/en/\#home (accessed on 25 September 2018).

5. Ministry of Food and Agriculture. Agricultural Sector Progress, Report 2016; Ministry of Food and Agriculture: Accra, Ghana, 2017.

6. Dzomeku, B.M.; Boateng, O.K. Exploring the potential of banana sap as dye for the Adinkra industry in Ghana. J. Ghana Sci. Assoc. 2012, 14, 20-24.

7. Asare, I.T. Critical success factors for the revival of the textile sector in Ghana. Int. J. Bus. Soc. Sci. 2012, 3 , 307-310.

8. Adikorley, R. The Textile Industry in Ghana: A Look into Tertiary Textile Education and Its Relevance to the Industry. Master's Thesis, The Patton College of Education of Ohio University, Athens, OH, USA, August 2013. 
9. Naab, F.X. An Assessment of the Contribution of Cotton Production to Local Economic Development in Sissala East and West Districts. Master's Thesis, Kwame Nkrumah University of Science and Technology, Kumasi, Ghana, August 2015.

10. NAIP (National Agricultural Innovation Project). Development of Value Added Products from Banana Pseudostem; Navsari Progress Report; Navsari Agricultural University: Navsari, India, 2011.

11. Afribanana Products Limited. Available online: http://afribanana.co.ug/index.php (accessed on 25 September 2018).

12. German Bioeconomy Council. Further Development of the "National Research Strategy BioEconomy 2030"; Office of the Bioeconomy Council: Berlin, Germany, 2016.

13. German Bioeconomy Council. Global Bioeconomy Summit, Communiqué-Innovation in the Global Bioeconomy for Sustainable and Inclusive Transformation and Wellbeing. In Proceedings of the Global Bioeconomy Summit, Berlin, Germany, 19-20 April 2018.

14. Schneider, R. Tailoring the bioeconomy to food security. Rural 21 2014, 3, 19-21.

15. Virchow, D.; Beuchelt, T.D.; Kuhn, A.; Denich, M. Biomass-Based Value Webs: A Novel Perspective for Emerging Bioeconomies in Sub-Saharan Africa. In Technological and Institutional Innovation for Marginalized Smallholders in Agricultural Development; Gatzweiler, F.W., von Braun, J., Eds.; Springer International Publishing: Basel, Switzerland, 2016; pp. 225-238.

16. German Bioeconomy Council. Bioeconomy Policy (Part II)_Synopsis of National Strategies around the World; Office of the Bioeconomy Council: Berlin, Germany, 2015.

17. German Bioeconomy Council. Bioeconomy Policy (Part III)_Update Report of National Strategies around the World; Office of the Bioeconomy Council: Berlin, Germany, 2018.

18. Scheiterle, L.; Ulmer, A.; Birner, R.; Pyka, A. From commodity-based value chains to biomass-based value webs: The case of sugarcane in Brazil's bioeconomy. J. Clean. Prod. 2018, 172, 3851-3863. [CrossRef]

19. Poku, A.-G.; Birner, R.; Gupta, S. Making contract farming arrangements work in Africa's bioeconomy: Evidence from cassava outgrower schemes in Ghana. Sustainability 2018, 10, 1604. [CrossRef]

20. Leao, A.L.; Casarino, I.; Narine, S.; Sain, M. Innovation under the bioeconomy context. In Knowledge-Driven Developments in the Bioeconomy: Technological and Economic Perspectives; Dabbert, S., Lewandowski, I., Weiss, J., Pyka, A., Eds.; Springer: Cham, Switzerland, 2017; pp. 117-141, ISBN 978-3-319-58373-0.

21. Virchow, D.; Beuchelt, T.D.; Denich, M.; Loos, T.K.; Hoppe, M.; Kuhn, A. The value web approach-So that the South can also benefit from the bioeconomy. Rural 21 2014, 48, 16-18.

22. Porter, M.E. The Comparative Advantage of Nations; Free Press: New York, NY, USA, 1990.

23. Lundvall, B.-Å. National Innovation Systems: Toward a Theory of Innovation and Interactive Learning; Pinter: London, UK, 1992.

24. Freeman, C. Continental, national and sub-national innovation systems-Complementarity and economic growth. Res. Policy 2002, 31, 191-211. [CrossRef]

25. Context Network. Multi Crop Value Chain Phase II: Ghana-Plantain. Commissioned Report. 2014. Available online: https:/ / www.agriknowledge.org/downloads/dr26xx473 (accessed on 24 September 2018).

26. Schiffer, E. Net-Map Toolbox: Influence Mapping of Social Networks; International Food Policy Research Institute: Washington, DC, USA, 2007.

27. Gilbert, N. Researching Social Life, 3rd ed.; Sage: London, UK, 2008.

28. Cauthen, J.; Jones, D.; Gugerty, M.K.; Anderson, L. Banana and Plantain Value Chain: West Africa; Evans School Policy Analysis and Research (EPAR) Brief; Evans School Policy Analysis and Research: Seattle, WA, USA, 2013; Volume 239.

29. Anonymous; (COCOBOD, Sunyani, Brong-Ahafo, Ghana). Personal communication, 2016.

30. Padam, B.S.; Tin, H.S.; Chye, F.Y.; Sbdullah, M.I. Banana by-products: An under-utilized renewable food biomass with great potential. J. Food Sci. Technol. 2012, 51, 3527-3545. [CrossRef] [PubMed]

31. Uma, S.; Kalpana, S.; Sathiamoorthy, S.; Kumar, V. Evaluation of commercial cultivars of banana (Musa spp.) for their suitability for the fibre industry. Plant Genet. Resour. Newsl. 2005, 142, 29-35.

32. Adeniji, T.A.; Tenkouano, A.; Ezurike, J.N.; Ariyo, C.O.; Vroh-Bi, I. Value-adding post-harvest processing of cooking bananas (Musa spp. AAB and ABB genome groups). Afr. J. Biotechnol. 2010, 9, 9135-9141.

33. Mensah-Bonsu, A.; Agyeiwaa-Afrane, A.; Kuwornu, J.K.M. Efficiency of the plantain marketing system in Ghana: A co-integration analysis. J. Dev. Agric. Econ. 2011, 3, 593-601. 
34. Banful, A.B. Production of plantain, an economic prospect for food security in Ghana. In Bananas and Food Security, Proceedings of the INIBAP International Symposium, Douala, Cameroon, 10-14 November 1998; Picq, C., Fouré, E., Frison, E., Eds.; INIBAP: Montpellier, France, 1998; pp. 151-160.

35. Katila, S. Between Democracy and Dictatorship: The Market Queen Institution of Ghanian Daily Markets. In State, Market and Organizational Form; Bugra, A., Üsdiken, B., Eds.; Gruyter Studies in Organization: Berlin, Germany, 1997; Volume 80, pp. 269-288, ISBN 978-3-11-080073-9.

36. Scheiterle, L. The Role of Institutions and Networks in Developing the Bioeconomy: Case Studies from Ghana and Brazil. Ph.D. Thesis, University of Hohenheim, Stuttgart, Germany, November 2017.

37. Scheiterle, L.; Birner, R. Gender, knowledge and power: A case study of Market Queens in Ghana. In Proceedings of the 2018 Annual Meeting, Washington, DC, USA, 5-7 August 2018; Agricultural and Applied Economics Association: Milwaukee, WI, USA, 2018.

38. Ortega, Z.; Morón, M.; Monzón, M.D.; Badalló, P.; Paz, R. Production of banana fiber yarns for technical textile reinforced composites. Materials 2016, 9, 370. [CrossRef] [PubMed]

39. Poku, A.-G. The New Wave of Contract Farming in Ghana: The Role of Contract Design in Facilitating Sustainable Outgrower Schemes; BiomassWeb Policy Brief; Center for Development Research: Bonn, Germany, 2018; Volume 2.

(C) 2018 by the authors. Licensee MDPI, Basel, Switzerland. This article is an open access article distributed under the terms and conditions of the Creative Commons Attribution (CC BY) license (http:/ / creativecommons.org/licenses/by/4.0/). 